\title{
MARCELO MARQUES SOBRE A APARÊNCIA E A CONTRADIÇÃO NA REPÚBLICA DE PLATÃO
}

\author{
Carolina Araújo*
}

RESUMO: Este trabalho se propõe a um diálogo com a obra de Marcelo Marques. Trata-se de uma tentativa de reconstrução, a partir de cinco artigos publicados, do que seria o argumento central de um livro sobre aparência e contradição na República de Platão; um livro que nunca veio a público devido à sua morte repentina. Partimos da apresentação do conceito de dialética como análise do aparecer e aplicamo-lo à tripartição da alma, mostrando que ela pode ser entendida como uma classificação de diferentes tipos de desejo. Na sequência, tratamos de explicitar como, segundo Marques, a distinção entre dóxa e epistémè, presente no quinto livro da obra, guardaria traços retóricos de exagero. A suposta distinção de seus objetos se reduziria àquela entre manifestações múltiplas e a unidade do ser das coisas. Finalmente, analisamos a tese de que uma teoria da valoração, introduzida no símile entre sol e bem, impede o colapso da distinção ontológica entre ser e aparecer. Um exame crítico dessa interpretação de Marques tem lugar ao longo da exposição, assim como um elogio a esse intérprete audacioso, que não poupou esforços para questionar o que se supôs como doutrina platônica.

PALAVRAS-CHAVE: Marcelo Marques; Platão; República; aparência; contradição.

\section{MARCELO MARQUES ON APPEARANCE AND CONTRADICTION IN PLATO'S REPUBLIC}

* Professora Associada, Departamento de Filosofia, Instituto de Filosofia e Ciências Sociais, Universidade Federal do Rio de Janeiro. Bolsista de Produtividade em Pesquisa, CNPq. correio.carolina.araujo @gmail.com

\footnotetext{
ABSTRACT: This paper aims at a dialogue with the work of Marcelo Marques. It is an attempt to reconstruct, after five published articles, what would be the central argument of a book on appearance and contradiction in Plato's Republic; a book that never came to the public due to his sudden death. We begin by introducing the concept of dialectics as the analysis of appearance and proceed to apply it to the tripartition of the soul, to the result of understanding it as a classification of different desires. Thereafter we aim to show how, according to Marques, the distinction between doxa and epistemè, found in Book V, would present rhetorical traces of exaggeration. The alleged difference between their objects would come to no more than that between multiple manifestations of things and the unity of their being. Finally we analyze the thesis that a theory
} 
of valuation, introduced in the analogy between the sun and the good, precludes the collapse of the distinction between being and appearing. A critical exam of Marques' reading is offered all along its presentation, as well as praise to this audacious interpreter, who saved no effort to put into question what was supposed to be Platonic doctrine.

KEYWORDS: Marcelo Marques; Plato; Republic, appearance; contradiction.

distância, diz Aristóteles, pode interromper a atividade da amizade, mas não a
dissolve, a não ser que ao longo do tempo os amigos se esqueçam um do outro. ${ }^{1}$
Um certo exercício da memória preserva a amizade, e nesse caso o exercício é a própria filosofia. Em 03 de agosto de 2016 fomos privados da companhia de um colega querido e filósofo de alma. Marcelo Marques faleceu precocemente deixando os amigos na terrível aporia da experiência da morte.

A Universidade Federal de Minas Gerais foi sua alma mater, onde se graduou (1983), obteve seu mestrado (1989) e tornou-se finalmente professor titular. Seu doutorado foi obtido na Université Marc Bloch, Strasbourg, França (1997) e por duas vezes realizou estágios de Pósdoutoramento: na University of Pennsylvania, EUA (2005), e na Universidade de Campinas (2014). Deixou-nos dois livros autorais: Platão, pensador da diferença: uma leitura do Sofista (Belo Horizonte, Editora da UFMG, 2006) e O caminho poetico de Parmênides (São Paulo, Loyola, 1990); além da organização de 6 outros volumes de coletânea, e das traduções de Thomas Robinson, A psicologia de Platão, e de Alasdair MacIntyre, Justiça de Quem? Qual racionalidade?. Somam-se a esses, vários capítulos de livro e artigos de periódicos. A morte fez com que Marcelo Marques deixasse inconcluso um projeto de pesquisa sobre a questão filosófica do prazer nos diálogos platônicos.

Eu creio que não há soluções para a dor da ausência; por outro lado, entendo que a filosofia é uma prática de problemas sem solução. Quando o pensamento procura explicar a ausência de um amigo, ele nos põe em diálogo com ele, talvez não como ele de fato foi, mas segundo as categorias de que dispomos para compreender a sua ausência. ${ }^{2}$ Essa permanência de alguém no pensamento dos outros, os antigos gregos chamaram de kléos, e eles nunca duvidaram, nem mesmo os mais céticos de seus filósofos, de que o kléos, de certo modo, vence a morte, imortaliza. ${ }^{3}$

Este texto é o meu exercício de pensamento dialógico sobre a ausência de Marcelo Marques. Um diálogo que passa, não sobre os últimos interesses dele sobre o prazer, mas sobre interesses que tínhamos em comum acerca do argumento central da República de Platão. Em uma das últimas conversas que tivemos, ele me disse que, ao fazer o seu memorial para

\footnotetext{
${ }^{1}$ Cf. Aristóteles, Ética a Nicômaco, 1157b10-12: oi yò

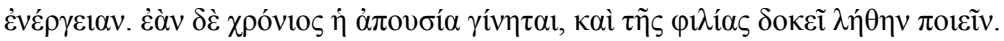

${ }^{2}$ Cf. Platão, Teeteto, 189e6-190e6, sobre o pensamento como diálogo, e 166a7-b1, sobre a projeção que fazemos do discurso daqueles que estão ausentes.

${ }^{3}$ Sobre kléos, cf. Nagy, 1974, p. 231-255.
} 
tornar-se professor titular na UFMG, tinha percebido que o grupo de cinco artigos publicados por ele sobre a República formaria um livro, que ele gostaria de publicar. Isso sugere que há uma tese unificada ao longo dos textos, fruto de um mesmo fôlego de reflexão, ainda que as datas da publicação variem e que a sequência cronológica das publicações não siga a sequência argumentativa. $\mathrm{O}$ que segue é a minha tentativa de reconstruir o argumento central desse livro inexistente.

\section{Aparecer e dialética}

Vale para a sua interpretação da República uma tese que Marques já havia formulado em relação ao Sofista (cf. Marques, 2006b), qual seja, a de que "a dialética platônica é um exame das diferentes modalidades do aparecer” (Marques, 2010a, p. 320). Essa é uma tese ao mesmo tempo metodológica, sobre o procedimento investigativo platônico, e ontológica, sobre a realidade da aparência. Comecemos pelo segundo ponto.

O aparecer é o objeto de investigação filosófica (cf. Marques, 2009, p. 137) à medida que se constitui discursivamente sob a forma da contradição (cf. Marques, 2010a, p. 321). Isso se explica porque há modos distintos de aparecer, cada um deles relacionado a uma forma diferente de cognição (cf. Marques, 2009, p. 144); é a simultaneidade na sua apreensão que nos apresenta a contradição. Decorre daí que a aparência não é uma categoria perceptiva, mas uma formulação discursiva com pretensão de verdade: "guiar-se pelo aparecer não significa apenas aderir ao dado sensível, mas, também e principalmente, aceitar algo que é tido como verdadeiro.” (Marques, 2011, p. 245). Por sua vez, é essa a forma contraditória que garante que o aparecer não é, como talvez quisesse uma certa vertente do platonismo, algo a que não cabe realidade; ao contrário, nas palavras de Marques: "o que aparece não é pura negatividade, mas conflito ou contrariedade” (Marques, 2009, p. 162).

Dada essa qualificação da aparência como conflituosa e contraditória, a sua inteligibilidade, diz Marques, depende de um critério de verdade e análise, que Platão postula, a contrario sensu, como o que é invisível e inteligível (Marques, 2009, p. 154):

...'aparecer como imagem' significa ainda ser a representação inteligente e inteligível de processos e relações, de modo ainda dependente do plano tangível ou visível, mas que, por sua inteligência mesma, por sua contrariedade (ou pelos conflitos que lhe são inerentes), pela elaboração reflexiva que exige, é caminho para mais inteligibilidade, é passagem propícia para a essência inteligível, que, por sua vez, aponta para além de toda imagem. (Marques, 2009, p. 165)

É essa explicação do visível por critérios inteligíveis que caracteriza o exercício da dialética. Nesse sentido, ela se configura como um procedimento contínuo de análise - “a intelecção ou a ciência é pensada como processo (movimento do psiquismo) e progressiva

\footnotetext{
${ }^{4}$ Marques, 2006a, 2009, 2010a, 2010b e 2011.
} 
compreensão (dialégesthai)" (Marques, 2009, p. 138) - baseado na suposição metódica de que as coisas que nos aparecem são imagens de outras: "[Sócrates] compreende a experiência direta que temos das coisas a partir da relação que temos com as imagens em geral, ou seja, constrói a realidade imediata (sensível e opinativa) como imagem" (Marques, 2009, p. 139). O resultado desse exercício é um conhecimento muito singular: "Podemos falar, então, de uma espécie de conhecimento pela imagem, no sentido de um reconhecimento da imagem enquanto imagem" (Marques, 2009, p. 139).

Há bastante evidência de que essa descrição do procedimento dialético sobre a aparência Marques a toma da República, mais especificamente da descrição dos estados da alma que encontramos na analogia da linha dividida (509e6-511e5). ${ }^{5}$ Eis como ele descreve a segunda seção da linha dividida, atribuída à pistis:

Trata-se, portanto, nesta seção, das coisas ou dos seres pensados como imagem de alguma outra coisa. Pensar os seres que são objetos da percepção sensível como imagens significa pensar, primeiro, que são efetivamente o que são, ou seja, múltiplos e diversos; em segundo lugar, que são marcados por alguma insuficiência (tomando "ser" no sentido predicativo, ou de determinações parciais); e, em terceiro lugar, que são contraditórios ou marcados por determinações contrárias. (Marques, 2009, p. 161-162)

Essa análise das imagens e seus desdobramentos Marques vê em cena nos principais argumentos da República de que trataremos aqui: a identificação de uma natureza única em homens e mulheres (451b8-457d5), a análise da unidade e da multiplicidade do belo (474b3480a13) e a tripartição da alma, que ele considera como uma analítica do desejo (435d9-441c3).

\section{A ALMA}

Voltando-se ao chamado argumento da tripartição da alma (435d9-441c3), e sempre pautado pela tese ontológica e metodológica acima apresentada, Marques pretende ressaltar o papel que desempenham as modalidades do aparecer na definição do desejo: "há no apetite uma demanda da aparência ou do aparecer sem a qual ele não funcionaria" (Marques, 2010a, p. 327). Ora, dada a suposição de que a aparência é a formulação discursiva de uma contradição, podemos entender que todo desejo é expresso segundo uma contradição. Não por outro motivo, Marques entende que Platão formula a sua descrição do funcionamento do desejo segundo o que chama de "princípio de não contradição psíquica" (Marques, 2010a, p. 323). Eu tenho dificuldades em aceitar esse nome, por isso gostaria de chamar atenção à tradução do grego proposta por Marques (com a minha tradução do francês para o português):

\footnotetext{
${ }^{5}$ As referências unicamente numéricas referem-se à República de Platão, edição Slings, 2003.
} 


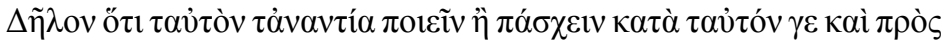

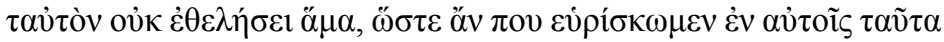

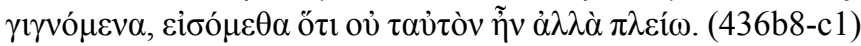

É visível que a mesma coisa não consentirá em fazer ou em sofrer simultaneamente coisas opostas, (a) em todo caso, (b) sob a relação da mesma coisa e (c) em relação à mesma coisa; por consequência, se por acaso nós descobrirmos que isso se produz nesses tais atos (nessas ações e paixões), saberemos que não era a mesma coisa, mas muitas, que fazem ou sofrem isso. (Marques, 2010a, p. 323)

Duas observações conceituais. Primeiramente há qualificações a definirem a oposição que é vetada: (a) é uma qualificação temporal, (b) é uma qualificação em relação a si mesmo e (c) é uma qualificação relativa a outro. Em segundo lugar, ação e afecção, na passagem, têm o propósito de abarcar um amplo espectro de movimentos cujas especificações não vêm ao caso. Parece-me que Marques concordaria com isso, tendo em vista a sua descrição do plano geral do argumento: "trata-se dos movimentos psíquicos, dentre os quais se enfatiza aqueles que se opõem, de modo que o debate acabará por levar a uma verdadeira teoria da ação" (Marques, 2010a, p. 324). Assim, para simplificar, restrinjamos nossa análise à ação, supondo que ela também seja válida às afecções.

O princípio então diz que um item A não suporta ser agente de contrários qualificados, porque isso indica que a individuação do agente não corresponde ao caso. $\mathrm{O}$ agente se constitui pela ação - e não vice-versa. Se agora voltamos ao nome "princípio de não contradição psíquica", vemos que ele indica que a alma não pode estar em contradição, entendendo por contradição duas proposições incompatíveis sobre si mesma. A conclusão seria que, por exemplo, "a alma deseja beber essa água” e "a alma deseja não beber essa água” seriam formulações incompatíveis que deveriam ser substituídas por algo como "o desejo deseja beber essa água" e “o raciocínio deseja não beber essa água”. A meu ver, é claro que Sócrates pretende o segundo tipo de explicação, mas ele não pode alegar a incompatibilidade das proposições do primeiro tipo. Ao contrário, ele quer explicar porque não é contraditório dizer que a alma deseja $e$ não deseja essa água. ${ }^{6} \mathrm{E}$ por isso que me parece que não pode haver aqui um impedimento à contradição psíquica.

Eu entendo que Marques pudesse abrir mão dessa tese em nome de uma outra que ele claramente sustenta, a da unificação da alma pelo desejo. Também nessa tese eu vejo dificuldades, embora não intransponíveis. Marques entende essa "oposição dos movimentos psíquicos" segundo categorias de "querer atrair para si" ou "querer repelir de si":

A análise minuciosa mostra como desejar equivale a querer atrair, a aprovar alguma coisa e a tentar tê-la consigo. Ao contrário, não querer, não consentir e não desejar são postos ao lado do rejeitar e do repelir, isto é, de tudo o que é contrário aos movimentos anteriores. (Marques, 2010a, p. 324)

\footnotetext{
${ }^{6}$ A tese da contradição, tal como eu a apresento aqui, parece resultar em que a alma não pode mais ser unificada enquanto agente. Cf. Annas, 1981, p. 137-146 e Bobonich, 2002, p. 219-235.
} 
Essa categorização dos movimentos psíquicos faz com que todos eles compartilhem a mesma natureza de ser desejo como princípio de movimento, caso em que a repulsão deve ser entendida como o desejo do contrário. Na alma o desejo não é portanto restrito à epithymía, que passa - ao menos no argumento do livro IV - a ser interpretada como uma espécie de desejo. A dificuldade que se apresenta agora é a da explicação do conflito. Reduzir a repulsa a um desejo do contrário é não explicar como a alma pode desejar e repelir um mesmo objeto. Em nossa primeira hipótese, a explicação do conflito psíquico seria de que "o desejo deseja beber essa água" e "o raciocínio deseja não beber essa água", sendo "beber essa água" o contrário qualificado que individua o agente. Porém agora o conflito teria que se explicar, por exemplo, pelo fato de "o raciocínio desejar a saúde" - no caso, digamos, de a água não ser potável - e com isso nós não temos mais o contrário qualificado que possibilitava a distinção de agentes. Eu creio ser possível montar um argumento que preserve o contrário qualificado, mas ele depende da concessão de que haja um processo inferencial do raciocínio que o leva a identificar a saúde com "não beber essa água". O ônus dessa hipótese é que o ato de repulsa teria que ser caracterizado como uma ação de segunda ordem ${ }^{7}$, o que traria sérias consequências à tese de que a alma se unifica pelo desejo.

Eu entendo que Marques objeta, como evidencia a última citação, à distinção entre desejo e recusa. Ele pagaria esse preço pelo bem da sua interpretação geral. É uma conclusão minha, mais do que algo explícito no seu texto, que Marques entende que o argumento da tripartição da alma parte da suposição de que há um gênero comum a todas as partes da alma, o desejo, e segue ao longo da individuação das suas diferenças específicas. Evidência para sustentar essa minha conclusão se apresenta na sua análise sobre o desejo.

\section{O DESEJO}

À tese de que as partes da alma são diferentes espécies de desejo são adicionadas duas outras teses: (i) o desejo é um conceito relativo, definido pelo seu objeto, que é um modo do aparecer e (ii) "todo desejo é desejo do que parece ser bom a quem deseja" (Marques, 2010a, p. 324). A primeira tese tem duas partes: a primeira está literalmente expressa no texto platônico (437e7-8) - o desejo é um relativo e se define pelo seu correlativo -, mas a segunda - o objeto do desejo é um modo do aparecer - é interpretativa. Ela supõe, entendo eu, o já referido conceito de aparecer como contrariedade, de modo que o desejo se manifesta internamente a um conflito. Por sua vez, a segunda tese atribui um sujeito a essa aparência que constitui o objeto do desejo: é um aparecer do bem. Entendo que isso signifique que o desejo se explica como um conflito entre formulações incompatíveis do que é bom. Essa pouco ortodoxa relação entre desejo, bem e aparência, Marques a defende a partir de três passagens, que ele cita fora da ordem em que aparecem, introduzindo uma concatenação que é relevante ao seu argumento. Cito a sua tradução (vertida por mim para o português):

\footnotetext{
${ }^{7}$ Sobre ações de segunda ordem, cf. Lorenz, 2004.
} 


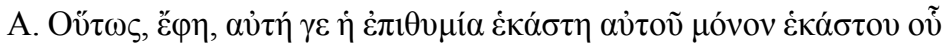

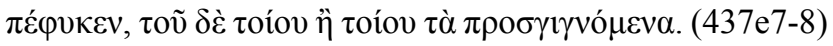

Está bem, disse ele: cada desejo (apetite), ao menos em si mesmo, é somente desejo daquela coisa única de que ele é naturalmente desejo; quanto ao desejo de uma coisa de tal ou tal qualidade, isso se produz adicionalmente. (Marques, 2010a, p. 324)

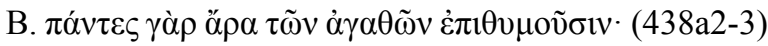

É bem certo, com efeito, que todos desejam o que é bom. (Marques, 2010a, p. 324)

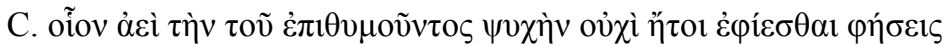

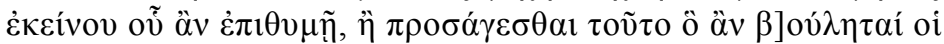

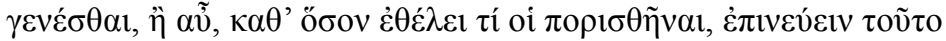
$\pi \rho$ ò $\varsigma \alpha \dot{v} \tau \dot{\eta} \nu$

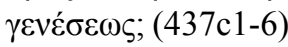

Assim, a cada vez, a alma daquele que deseja, não afirmarás que ela cobiça o que ela deseja, ou que ela atrai para si aquilo que ela quer possuir, ou ainda que, à medida que ela quer que alguma coisa lhe seja proporcionada, ela diz a ela mesma, como se alguém lhe perguntasse, que ela prova essa coisa, desejando que ela se produza? (Marques, 2010a, p. 324)

A passagem $C$ antecede as outras duas no argumento, mas Marques entende que $\mathrm{C}$ está intimamente ligada a B, e que essas duas completam A. Essa está longe de ser a leitura mais corrente do texto. Isso porque a leitura linear mostra que A explica C, como a conclusão de uma indução: como todo desejo é querer atrair algo, todo desejo tem um objeto intencional (ou ainda um item que lhe serve como o que chamamos de "contrário qualificado"). Ao descrever o desejo como um relativo em C, Sócrates pretende usar a distinção entre objetos intencionais para mostrar que, quando nos recusamos a beber água quando sedentos, isso não é sinal de um desejo contraditório em nós, algo que sequer podemos entender, mas de duas ações intrapsíquicas em conflito, ou, como queria Marques, dois desejos em conflito. Uma vez especificado o objeto de cada uma dessas ações internas, isso nos permite entender o que se passa interiormente em nós, ou seja, que temos desejo de beber essa água e uma razão para não bebê-la - como eu entendo - ou um desejo de não bebê-la - como Marques entende.

Se essa é a relação entre $\mathrm{C}$ e $\mathrm{A}$, a introdução de $\mathrm{B}$ parece trazer um novo problema à tona, na voz de alguém que protesta contra a tese da individuação dos desejos a partir do princípio de que ações identificam agentes. Esse objetor alega precisamente que o objeto natural do desejo é o bem, uma tese que, como o próprio Marques aponta, aparece na República tanto em 413a4-5, como em 505d5-9 (Marques, 2010a, p. 325). Como uma tese platônica - a do bem como objeto natural do desejo - pode ser objeção a uma tese platônica - a da especificação dos desejos por seu objeto natural? 
Eu entendo que é isso o que Platão está fazendo no livro IV: uma objeção à tese geral do bem como objeto natural do desejo por meio da tese dos objetos naturais que especificam desejos. Eu entendo que, a manter a ordem das citações no texto, essa leitura, que eu disse ser mais corrente, impõe-se sobre a solução de Marques. Ao inverter a ordem das citações, Marques, entretanto, consegue uma evidência a seu favor, qual seja, a de que a classificação dos desejos no livro IV é compatível com a tese de que "todo desejo é de uma aparência do bem". Para cada aparência como contradição podemos individuar desejos distintos em conflito. Há prós e contras nisso, mas primeiro precisamos desenvolver um pouco mais a questão.

A tese de Marques é a de que o objeto natural do desejo é a aparência do bem, e que é pela especificação das várias modalidades de aparência do bem que podemos compreender o conflito interno. Nesse sentido, ele diz que "a dimensão do espetáculo é decisiva para o mecanismo do desejo, ou, para dizer de outro modo, há no apetite uma demanda de aparência sem a qual ele não funcionaria" (Marques, 2010a, p. 327). Frente a esse espetáculo, "a operação [filosófica] consiste em diferenciar para tornar possível a consonância de opostos" (Marques, 2010a, p. 327), ou seja, há aqui uma investigação, que daqui por diante chamaremos de operação dialética, da aparência do bem pela especificação dos desejos nela em conflito. A operação dialética sobre as ações intrapsíquicas não é possível imediatamente à alma que delas é sede, mas apenas pela mediação de um escrutínio de cada uma delas: "Naquilo que era visto como um mesmo [a alma], Sócrates distingue o mesmo do outro" (Marques, 2010a, p 329). Eis que temos mais um problema: ser capaz de compreender nossas ações intrapsíquicas por esse método dialético ainda não é ser capaz de transformar o conflito em uma "consonância".

A compreensão das ações intrapsíquicas é necessária, porém não suficiente à excelência da alma defendida no livro IV da República. A excelência depende de uma certa solução desse conflito, indicada por termos como "consonância" e "harmonia" (cf. 442c6, 9, 443d5-6, e2), na qual o sucesso não pode ser simplesmente a vitória do mais forte pela supressão dos demais desejos. Quando perguntamos a Marques: “- Como agimos de modo excelente?”, a resposta parece ser a de que a excelência está em fazer vencer o raciocínio. Em suas palavras: "colocar-se a questão da qualidade do objeto do desejo, a questão de saber se isso que parece ser bom o é realmente" (Marques, 2010a, p. 325). Entendo que a conclusão de Marques é de que a consonância de todos os nossos desejos repousa na vitória de um deles. Há algo de paradoxal nessa tese, algo que se assemelha, mutatis mutandis, ao estranho argumento de Agatão no Banquete de que Eros é o mais temperante dos desejos porque controla pela força, impondo limites a todos os demais (Platão, Banquete, 196c4-8).

Comparemos essa última citação de Marques com a tese de que todo desejo é de uma aparência do bem. Como vimos, segundo essa premissa, é o conflito sobre o bem, próprio à aparência, que nos permite identificar os desejos em causa. A última citação, por sua vez, atrela a solução do conflito a algo que não é aparentemente bom, o que decorre obviamente da tese de que aparência e conflito vêm juntos. Mas o preço que ela tem que pagar é de que, 
por definição, o bem que soluciona um conflito não pode ser aparente, não pode aparecer. A última citação distingue ser e aparecer como incompatíveis.

O resultado é que, para sustentar que todo desejo é de uma aparência do bem, é preciso ou (i) desvincular aparência de conflito e contradição - o que era premissa básica de Marques - e aceitar que o desejo pode ser do bem real ou ainda que o bem real pode aparecer, uma tese que eu chamaria de "aparecer do ser"; ou (ii) manter o vínculo entre desejo, conflito e aparência, mas negar a unidade da alma pelo desejo, e aceitar que a operação dialética é de segunda ordem, realizada por uma ação intelectual de compreensão do bem real, uma tese que eu chamaria de "distinção entre desejo e intelecto". Para que Marques defenda o aparecer do ser, ele deve propor critérios de diferenciação entre bem real e aparente que não sejam o conflito e a contradição. Para que alguém assuma a distinção entre desejo e intelecto, é preciso explicar como uma ação não desiderativa pode solucionar um conflito entre desejos, problema pertinente ao contexto do livro IV, em que, ao que parece, a incontinência (akrasía) é possível. ${ }^{8}$

Seguindo minha formulação, entendo que Marques toma o primeiro caminho, sustentando que o bem tem aparências diversas, todas elas contraditórias entre si à exceção da "aparência" que é o seu próprio ser. Assegurado que o raciocínio é um tipo de desejo pelo bem real, conclui-se que a sua vitória não é impositiva como o Eros de Agatão porque ela é verdadeira, ou seja, porque ela se apresenta aos demais desejos como correspondendo ao que realmente eles buscavam ao serem conduzidos pelas aparências. Essa é uma via argumentativa muito interessante, que indica uma certa persuasão pragmática da razão sobre os demais desejos quanto ao valor intrínseco do seu controle. Mas ela supõe que os demais desejos tenham também essa capacidade de compreensão, que eles não sejam apenas definidos pelo tipo de ações e afecções da alma que representam. Marques subscreve a essa proposta. Ele reconhece que há uma função cognitiva e um grau de racionalidade em todos os desejos uma vez que identificam seus objetos intencionais, as aparências do bem. Isso faz com que ele precise supor - e aqui começa o problema - que essa racionalidade tem fins próprios, que caracterizam o tipo de desejo que ele é: por exemplo, os apetites se definiriam por princípios de repleção e gozo (Marques, 2010a, p. 331-332).

Entendamos o problema. Segundo Marques, a repleção é uma aparência do bem fruto de uma certa cognição contraditória e conflituosa do que o bem é, ou seja, ela é uma dóxa do bem que causa na alma a afecção do apetite (Marques, 2010a, p. 331). Agora vemos que há um ato cognitivo específico que apresenta à alma o objeto que lhe causa certo movimento. ${ }^{9}$ Mas isso não é tudo. A essa dóxa corresponde um objeto que tem um determinado conteúdo,

\footnotetext{
${ }^{8}$ Cf. Platão, República, 439e5-440b8. Para uma tentativa de minimizar o impacto dessa passagem enquanto uma teoria da incontinência, cf. Shields, 2007.

${ }_{9}^{9}$ Assim como antes não fazia muita diferença falarmos de movimentos ativos ou passivos da alma em relação a certo objeto, agora vemos que a constituição cognitiva desses objetos também pode ser igualmente descrita em termos ativos ou passivos: a aparência afeta a alma (dóxa em sentido objetivo e passivo), a alma tem um parecer (dóxa em sentido subjetivo e ativo). Para a distinção entre os sentidos objetivo e passivo cf. Lafrance, 1981, p. 19-33.
} 
no caso dos apetites, a repleção. Por outro lado, o raciocínio parte de objetos que não se apresentam à cognição do mesmo modo que os objetos do apetite, i.e., não são objetos de dóxa, mas de epistếmè embora sejam igualmente correlativos de movimentos psíquicos. Esses objetos são as "formas inteligíveis" (Marques, 2010a, p. 329) e devemos supor, para garantir a tese do valor intrínseco da vitória do raciocínio, que elas têm um conteúdo indicativo de harmonia e consonância. Se é esse o nosso cenário conceitual, então temos dois problemas: (a) os objetos dos diferentes desejos se diferenciam por seu acesso cognitivo e (b) os objetos dos diferentes desejos se diferenciam por seu conteúdo.

O ponto (a) se descreve como a prioridade lógica (ou explicativa) da constituição cognitiva - via dóxa ou via epistémé - dos objetos do desejo - apetitivos ou racionais - em relação ao método de individuação estabelecido pelo princípio, que, ao que vimos, definia agentes por suas ações. Passamos a uma etapa explanatória anterior na qual não se trata mais de partir das ações para identificar agentes, mas de partir da cognição de determinados objetos para explicar determinadas ações. ${ }^{10}$ Nesse sentido, o raciocínio se diferencia do apetite, e de todos os demais desejos, porque o seu objeto é aquele que afeta a alma apenas ao final de uma operação dialética, que é distinta do processo de cognição dos objetos dos outros desejos. Assim, segundo Marques, o livro IV trata da "gênese das forças psíquicas" (Marques, 2010a, p 331) e o seu argumento continua com a exposição de um elemento logicamente anterior, qual seja, a cognição dos objetos que geram essas forças, o que acontece no livro V. Essa linha argumentativa será desenvolvida na próxima seção.

O ponto (b) consiste em um desafio bem mais robusto para a tarefa que Marques se propõe a realizar, uma vez que ele sugere que há uma diferenciação de conteúdos, e não simplesmente de acessos cognitivos, entre os objetos do apetite e do raciocínio. No contexto mais amplo, isso implica que os conflitos nos quais se insere o desejo ocorrem porque os propósitos em choque são irredutíveis. Se o agente se define pela busca da repleção, não há como ele se persuadir de que a harmonia lhe oferece uma versão mais genuína de seu alvo. A vitória do raciocínio terá que passar por uma efetiva submissão do apetite, à maneira do Eros de Agatão, e não pela sua persuasão. Na seção 6 trataremos de como esse problema coloca Marques em um impasse.

\section{DóXa e EPISTÉME}

Marques entende que o argumento do livro V, que, como vimos, fundamenta cognitivamente o argumento do IV, é um único argumento no qual "as duas primeiras ondas preparam a recepção da terceira, que é a maior e a mais difícil” (Marques, 2006a, p. 249). No seu entender trata-se, em todo o livro $\mathrm{V}$, de um argumento paradoxal:

\footnotetext{
${ }^{10}$ Sobre a relação entre as partes da alma apresentadas no livro IV e as faculdades introduzidas no livro V, cf. Delcominette, 2008.
} 
Paradoxal, no sentido de ser contra o que geralmente aparece como sendo verdadeiro, o que não significa que sua estrutura seja tão oculta assim; a argumentação é feita através de propostas que vão contra o que é aparentemente válido, contra o que é aceito como verdadeiro pela maioria dos cidadãos, contra a dóxa estabelecida. (Marques, 2006a, p. 248)

Ser paradoxal é ir contra a dóxa, entendida no sentido de o que é aceito como verdadeiro, uma aparência tida como válida. Temos então, seguindo a sugestão de Marques, que a distinção entre dóxa e epistémè sobre um assunto é praticada na primeira onda (451b8457d5), para depois ser analisada categorialmente na terceira onda (473c6-480a13). No argumento sobre o compartilhamento de funções entre homens e mulheres (451b8-457d5), a distinção se apresenta do seguinte modo:

Parte da dóxa, i.e., o que se considera verdadeiro:

1. ...leva(r) em conta um certo relativismo cultural, criticando a dóxa ou o que é considerado bom e aceitável para a educação das mulheres; estas coisas pareceriam ridiculamente contrárias ao costume (parà tò éthos geloîa àn phainoito) se praticadas deste modo (452b). (Marques, 2010b, p. 431)

Tem como propósito a epistémē do bem sobre a distribuição das funções:

2. O sentido da discussão, no fim das contas, é que o que é bom para a cidade deve ser defendido argumentativamente e mostrado como sendo de acordo com o que é bom em si. (Marques, 2010b, p. 432).

Procede rejeitando contradições sobre o assunto:

3. É preciso, então, desfazer a contradição; quando atribuíram diferentes ocupações a naturezas diferentes e as mesmas ocupações a naturezas que são as mesmas, eles (os erísticos) não examinaram que diferença e que identidade estavam exatamente em questão. (Marques, 2010b, p. 434)

Conclui por estabelecer a distinção entre dóxa e epistêmé relativas à distribuição de funções:

Podemos dizer que há pelo menos dois planos fundamentais nos quais podemos pensar o conceito de natureza (physis), no livro V, distinção que é retomada e reforçada pelo final do livro, quando são estabelecidas as diferenças entre os objetos da opinião e da ciência. Por um lado, a natureza pensada como essência, que unifica o gênero humano $(\mathrm{V}$ 452e6-453a4) e que efetivamente justifica a formação comum a homens e mulheres (...) Por outro lado, as naturezas particularizantes e distintas do homem e da mulher, que justificam suas funções reconhecidamente diferentes na cidade hoje (V 453b7-c6). (Marques, 2010b, p. 439) 
A identidade de naturezas entre homens e mulheres, portanto, é um objeto de epistémè a que Sócrates chegou por meio da rejeição das contradições da dóxa sobre o assunto. A transição entre os dois modos cognitivos é feita pelo que Marques chama de "pensar por paradigma", ou seja, "postular um modelo puramente inteligível como medida", modelo que, quero entender, se define pela ausência de contradições. É assim que a transição é feita exatamente pela operação dialética que descrevemos no início desse texto como sendo contínua: "Definir não significa reduzir a termos logicamente codificados, mas desnudar algo progressivamente, ou seja, purificá-lo, fazendo aparecer, a cada vez, a estrutura inteligível que o determina" (Marques 2006a, p. 255-256).

Se, por um lado, podemos concordar com a descrição do método, por outro, a formulação dos pontos de partida e de chegada é mais problemática. Isso porque, sustentando que o livro V funciona como um argumento unificado, Marques acaba por descrever a dóxa como: "um estado difuso de consciência, menos claro e menos preciso, porque não distingue, não mostra diferenças, não conhece efetivamente aquilo a que se refere" (Marques, 2006a, p. 262). De minha parte, tenho muita dificuldade em subscrever a tese de um estado difuso de consciência. Passo a explicar essa dificuldade, começando por apontar que os que, no argumento de Sócrates, defendem a diferença de natureza entre homens e mulheres não têm simplesmente uma visão embaçada sobre a natureza, eles têm uma concepção equivocada do que ela seja (cf. 454a1-b3). O que se conclui do argumento sobre a distribuição de funções não é que a concepção de educação feminina é vaga, imprecisa, ao contrário: ela é errada (cf. 456b4-10). Meu ponto é que não basta entender que a dóxa é uma modalidade menos clara do que a epistếmè, é preciso dizer que ela pode estar errada e a epistếmé não.

Ao sugerir que a dóxa é um certo modo obscuro da epistémé, Marques rejeita que a distinção entre elas deve ser feita segundo uma diferenciação de objetos (Marques, 2006a, p. 263). Ele afirma que o objeto da dóxa é a multiplicidade de manifestações da forma ela mesma, que é o objeto da epistếmē: "A forma, que é uma, aparece como sendo múltipla (perspectiva ontológica) (...) Portanto, o objeto da ciência também se submete a diferentes apareceres”. (Marques, 2006a, p. 265-266). Temos aqui literalmente expressa a tese anteriormente indicada de que o aparecer é contraditório apenas quando ele não é real, e que o real pode aparecer sem a contradição. É assim que o aparecer reúne os objetos que a princípio deveriam ser distinguidos: "Os objetos (visíveis e inteligíveis) e os modos de acesso a eles se diferenciam, mas não se divorciam; eles se relacionam, mesmo que o façam através de imitações imperfeitas" (Marques, 2011, p. 250). Ao supor que o objeto da dóxa é a manifestação visível/tangível do objeto da ciência, a conclusão de Marques é de que a descrição da epistémé como infalível em 477e7-8 - por oposição a uma dóxa que pode estar errada - é retórica, no sentido mais vulgar do termo:

O exagero trai a situação retórica particular, pois, neste momento do diálogo, trata-se de construir uma diferença e de sustentar uma tese inaceitável: a legitimação do poder do filósofo, pelo tipo de saber a que ele aspira ou tem acesso. (Marques, 2006a, p. 263)

Classica, v. 31, n. 1, p. 179-197, 2018 
Já expus uma das razões das minhas reservas a essa leitura. Passo agora a tratar do que me parece ser o caminho que o levou a uma posição tão radical, um caminho que começa pelo combate contra o que se chama de "teoria dos dois mundos". Tradicionalmente imputada a Platão, a teoria dos dois mundos tem formulações diversas, mas todas elas partem do princípio de que, ao postular as formas como os únicos itens que são, Platão indica um mundo composto por esses itens que é distinto dos itens que compõem o nosso mundo, que são perecíveis, relacionais, em movimento. Assumir a tese do "aparecer do ser" é a estratégia de Marques para combater os dois mundos: se os itens que são aparecem, eles estão no nosso mundo, tanto quanto aqueles transitórios ou, mais especificamente, como a causa deles:

Reconhecer diferenças não implica necessariamente em isolá-las em âmbitos paralelos. Se admitirmos que uma esfera seja causa da outra, já estamos na direção da superação desse tipo de visão. A meu ver, por definição, basta um ponto de contato entre duas supostas paralelas para que não sejam mais tidas como tais, pois, efetivamente, não se trata de linhas cujo cruzamento seja fortuito. (Marques, 2011, p. 246)

O que vemos aqui formulada é a suposição de que combater os "dois mundos" é apenas uma questão de mostrar como há relação entre esses dois tipos de objeto - formas e perecíveis - no mundo. Mas essa suposição de que "basta um ponto de contato" caracteriza o problema indevidamente. O ponto nevrálgico desse platonismo reside na atribuição de existência independente, ou se se quiser de substancialidade, não apenas aos "objetos inteligíveis", mas também aos "objetos sensíveis". O problema é que, ao tentar negar a distinção dos objetos, Marques o faz precisamente supondo a existência dos chamados "objetos sensíveis". Em sua análise sobre os usos do verbo ser no argumento final do livro $\mathrm{V}$ da República, ele insiste em que há um sentido existencial do verbo inegável na passagem e que esse sentido deve ser atribuído aos objetos da dóxa:

O "é" existencial não significa que a existência deva ser pensada como sendo totalmente separada, mas pode ser tomado como indicando existência, mais ou menos determinada, de modos diferentes. O 'é' predicativo não determina algo que não existe, mas remete o ser em questão à forma inteligível pela qual ele é o que é. Ser significa existir e ainda ser algo determinado, de um modo ou de outro. Mas se reunirmos as duas significações, simplesmente tomando existir como sinônimo de ser determinado, a aporia persiste; existir não pode ser exatamente o mesmo que ser determinado, pois é o grau de determinação que varia; tudo o que é tem alguma determinação; a determinação da forma inteligível nela mesma é total, ela é perfeitamente o que ela é; a determinação dos seres múltiplos é parcial e desigual, eles são imperfeitamente o que são, mas isso não pode implicar em sua existência parcial. A meu ver, a única maneira de superar essas dificuldades é explicitar as relações das formas com os gêneros maiores, que é o que Platão faz, no Sofista, através do Estrangeiro de Eleia. No caso da forma, 
é sua própria natureza que é fonte de determinação total ou perfeita; sua própria determinação, por ser o que é, e a determinação de outros seres, por participarem nela; no caso dos seres visíveis (múltiplos ou particulares), é sua participação em alguma outra forma, que não a do ser, que lhes dá sua determinação, qualquer que seja e em que grau que seja. (Marques, 2011, p. 257)

Ora, se as formas dão determinação a algo que preexiste ou existe independentemente delas, elas são propriedades que inerem no ser das coisas, e não o ser mesmo delas. O que temos aqui é apenas a versão microcósmica de uma teoria dos dois mundos, que agora precisa explicar como um item independente pode ser a propriedade de um outro item independente. A meu ver Marques é levado a se comprometer com a tese que ele visava combater por causa da sua dificuldade em dar conta do que caracterizei como sendo o desafio de defender o "aparecer do ser", i.e., de apresentar critérios de diferenciação entre ser e aparecer. Em última análise, tanto os objetos da dóxa, quanto os objetos da epistếmè são descritos como "o aparecer do ser", os primeiros como a "aparência do ser" e os últimos como o "modo de aparecer do ser". A não ser que se explique como a expressão é equívoca, não vejo saída para o problema.

Pois bem, eu não sei como Marques responderia a essas perguntas, mas nada me impede de colocá-las, de continuar imaginando como ele responderia e de, assim, dar continuidade à nossa amizade. Por isso, eu continuo a conversa supondo que ele pretende uma certa unificação dos objetos da dóxa e da epistéméa partir da qual pode sustentar a tese de que a dialética platônica é um exame das diferentes modalidades do aparecer porque analisa o aparecer das formas, depurando, na sua manifestação, aquilo que não é a sua natureza.

\section{O BEM}

Como vimos até aqui, Marques defende que há em Platão uma unidade entre ser e aparecer, de modo tal que aparecer é uma manifestação do ser e que o ser ele mesmo aparece. Também vimos que algum argumento é necessário para estabelecer critérios de diferenciação entre ser e aparecer, de modo que "o aparecer do ser" não seja uma expressão sempre equívoca, resultando finalmente em um colapso na diferença entre esses modos. Um dos modos de lidar com esse desafio é indicar que há uma certa diferença de conteúdo entre ser e aparecer, uma diferença que já foi indicada no ponto (b) sobre a distinção entre os objetos do desejo e do raciocínio. Naquele momento já apontamos algumas dificuldades sobre essa opção, agora tratamos de como Marques trata o problema.

Ao longo da referida série de artigos, Marques aponta apenas um argumento em que essa diferença entre ser e aparecer é defendida por Platão na República: o seu tratamento da forma do bem, especificamente tal como ele aparece em 505a3-506a7. Ele propõe que é porque nós não desejamos o bem aparente, mas apenas o bem real (505d5-10), que precisamos supor a distinção entre ser e aparência, e que não é por outro motivo que o problema do 
bem é central na República. Marques apresenta diferentes formulações dessa tese, as quais gostaria de discutir:

a) ninguém quer alguma coisa boa que é só aparentemente boa ou que é tida como tal, sem sê-lo. (Marques, 2009, p. 153)

b) é justamente na medida precisa em que a elaboração da questão do valor o exige, que serão buscadas as diferenças (ontológicas) entre aparecer e ser (assim como suas implicações epistêmicas). (Marques, 2009, p. 151)

c) é o bem que faz que haja diferenciação entre sensível e inteligível. (Marques, 2009, p. 155)

O que imediatamente notamos nessas formulações é que elas são feitas em bases primariamente (i) axiológicas e (ii) psicológicas. Seu argumento sobre o bem está fundado sobretudo na tese de que a aparência do bem pode se revelar má, ou como vimos, se o objeto do desejo é uma aparência do bem, aquela em que o bem aparece como repleção, essa aparência pode ser um mal. Tal abordagem axiológica apoia-se na tese primeira de que os estados intencionais da alma são todos eles desejo. Explico: a axiologia da distinção entre ser e aparecer supõe que a operação dialética que descrevemos no início desse trabalho é sempre uma variação de uma operação psicologicamente anterior, qual seja, a análise da aparência do bem. Se todos os movimentos da alma são desejo, negando, portanto, a distinção entre o desejo e o intelecto, a operação dialética é um recurso do desejo racional para apresentar a si mesmo o seu objeto. Responder à pergunta “o que algo realmente é?” não é senão um exercício do desejo de conhecer o que é o bem da alma como um todo e como esse item que investiga contribui para ele. Eu só investigo dialeticamente o que eu desejo conhecer porque suponho que esse conhecimento me será realmente bom.

A compatibilização entre a axiologia e a psicologia tem o grande mérito de explicar como o aparecer do bem pode ser mal sem, com isso, ser um aparecer do mal. Ela explica que o aparecer do bem é um mal à medida que toda aparência - à exceção da do ser - implica contrariedade. Desse modo a repleção é um mal ao mesmo tempo que um bem aparente. Ademais, que essa não seja uma aparência do mal se explica porque ela aparece como um objeto do desejo, portanto como algo a que se assente e não a que se recusa. O bem se identifica enfim com a intencionalidade entendida como grau žro do assentimento, de modo que todo aparecer seja um aparecer do bem.

Por outro lado, essa compatibilização entre a axiologia e a psicologia tem o ônus de explicar uma distinção ontológica em bases psicológicas. Parece não haver margem de dúvidas de que Marques esteja disposto a pagar esse preço:

Penso que este é um dos sentidos fundamentais da ideia do bem, enquanto princípio inteligível, aplicado ao exercício cognitivo: fazer com que quem pensa saiba fazer incidir o conhecimento maior da forma (do em si) na situação particular em questão, de acordo com as exigências 
do problema visado; o bem é, assim, um princípio de discernimento, que permite ao indivíduo pensar e saber o que é pensável e que, assim, é o melhor; ele é o valor (cognitivo, discriminador) maior que permite a inteligibilidade e o exame dos seres e dos valores em questão, caso a caso. (Marques, 2010b, p. 435-436)

Tenho sérias dúvidas em relação a essa abordagem do bem, mas nesse caso meus argumentos se referem à sua correspondência com o texto platônico. Um primeiro indício para essa suspeita é o modo como Marques se concentra no preâmbulo do tratamento da questão no livro VI (505a3-506a7), referindo-se apenas com muita parcimônia aos símiles do sol e da caverna que, na sequência, pretendem ilustrar a função ontológica da forma do bem. É um aspecto do texto platônico pouco explorado por Marques que a forma do bem tem uma função em relação às demais formas, expressa pela analogia que diz que tal como o sol é fonte de luz para os olhos e objetos visíveis, o bem é fonte de verdade para o intelecto e os objetos inteligíveis (cf. 508a12-c2). O princípio de inteligibilidade de que fala a última citação são as formas em geral, e não apenas a forma do bem (cf., por exemplo, 476a1-9), uma tese que Marques, como vimos na primeira seção, assume como base de sua interpretação da dialética platônica. Se assim é, para além dessa função explanatória comum a todas as formas, há uma peculiaridade da forma do bem na República, expressa no moto epékeina tês ousias (509b5-9), que se refere ao desempenho de uma função sistemática ou teleológica $^{11}$ - e não exatamente valorativa - no seio do pluralismo platônico. A meu ver, ao se centrar no preâmbulo do tratamento da forma do bem na República, Marques deixa de fora o problema da função do bem nessa organização estrutural da realidade em privilégio de uma abordagem psicológica:

O problema, então, não está com as diversas manifestações da beleza, enquanto tais, mas com a não-percepção da diferença; não há condenação das coisas belas, mas da não-distinção entre coisas belas e aquilo que as torna belas. Não há, tampouco, condenação do desejo ou do afeto, como vimos, mas uma crítica à confusão no estabelecimento de prioridades, no estabelecimento das diferenças de valor entre os diferentes objetos do desejo. (Marques, 2006a, p. 259)

A meu ver a função sistemática do bem dentro de um pluralismo ontológico é necessária inclusive para manter a interpretação psicológica que vemos aqui apresentada. Digo isso porque há um sério risco de circularidade pairando sobre ela. Como vimos, a tese de Marques é de que nossas faculdades desiderativas são individuadas pelos movimentos da alma que, por sua vez, são determinados pelos seus objetos próprios, objetos esses que se distinguem por suas vias cognitivas - dóxa ou epistếmé. As vias cognitivas, ao fim e ao cabo,

\footnotetext{
${ }^{11}$ Fundamental no sistema de Plotino, embora atribuída ao um (cf. Enéada, VI, 9), a função de princípio sistematizador da forma do bem persiste em interpretações tão variadas quanto Kramer, 1969, White, 1976 e Santas, 1983.
} 
determinam nossos desejos, uns baseados na aparência, outros na realidade. Há dois caminhos aqui. Tradicionalmente se justifica a distinção objetivamente: há itens aparentes e itens reais. Em oposição a esse tratamento, Marques sugere que a elaboração da questão do valor exige que façamos a distinção entre os objetos: a distinção entre aparência e realidade se impõe em nós por uma demanda do nosso próprio desejo que agora nos impele a distinguir nossas duas vias cognitivas. Em suma, a circularidade estaria em que o desejo determina a distinção das faculdades cognitivas que determina os objetos do desejo. No século XX a maneira mais usual de assumir essa tese e negar a sua circularidade foi assumir uma interpretação kantiana de Platão. ${ }^{12}$ Não vejo evidências nos artigos de Marques de uma adesão a essa interpretação, por isso não consigo dizer como ele evita a circularidade.

\section{Conclusão}

Eu tentei mostrar que Marcelo Marques tem uma interpretação singular dos livros centrais da República de Platão baseada na implicação entre as noções de aparência e contrariedade, e na compreensão da dialética como método de inteligibilidade do que é aparente e contrário. Esse método é primeiramente aplicado ao desejo no assim chamado argumento da tripartição da alma. Ali a alma seria definida como sede de vários movimentos, alguns deles contrários entre si. Essa contrariedade pode ser explicada segundo uma divisão de diferentes desejos de acordo com as aparências do bem que buscam. Entre os desejos, há os irracionais, que são os guiados pela repleção, e os racionais, que se guiam pela real natureza das coisas.

Essa classificação dos desejos só nos fica mais clara posteriormente, quando Marques indica que é o bem o que "torna possível a orientação ontológica do desejo" (Marques, 2009, p. 156): a distinção entre desejo de aparência e desejo do bem real seriam enfim uma divisão logicamente anterior à divisão da alma. Essa é a tese que permite a Marques compatibilizar duas teses sobre o desejo - a de que todo desejo tem um objeto natural e a de que todo desejo é desejo do bem. Ao entender que todo desejo é de uma aparência do bem real, a classificação dos desejos que partiria a alma se torna uma classificação de aparências. Ao que parece, esse argumento manteria a unidade da alma, o que não deixa de ser interessante como estratégia interpretativa de Platão. No entanto, ele possui algumas dificuldades. Eu formulei a minha objeção alegando que os objetos da dóxa não são simplesmente manifestações do objeto do conhecimento, eles são por muitas vezes a sua própria antítese.

Ainda assim Marques sustenta que Platão pensou o conhecimento como progressiva compreensão dos fenômenos considerados como imagens de algo, que é a sua verdadeira essência. Nossa apreensão primeira deve ser entendida como imagem para que possamos buscar o seu original. O objeto de nossa percepção deve ser considerado múltiplo, insuficiente e contraditório, para que ele seja o dispositivo acionador da busca pela unidade, a suficiência

\footnotetext{
${ }^{12}$ Para maneiras um tanto distintas de compreensão de um certo "transcedentalismo" platônico no qual a forma do bem opera como um diferenciador entre entedimento e razão, cf., por exemplo, Nartorp, 1994, Wieland, 1982 e Ferber, 1989.
} 
e a coerência que ele parcialmente manifesta. Tal como a real natureza do bem é a única que nos satisfaria, assim também seria com a real natureza das coisas que nos aparecem. Por esse argumento é a dinâmica de nossos desejos que nos impõe o reconhecimento da distinção ontológica. Se Marques foi capaz de evitar a circularidade que, como tentei mostrar, assombra esse argumento, teremos enfim diante de nós um Platão assaz interessante. Com essa sugestão, concluo minha homenagem, não sem dizer que perdemos não apenas um amigo, mas um intérprete audacioso, que não poupou esforços para questionar o que havia sido enrijecido como doutrina platônica.

\section{REFERÊNCIAS}

ANNAS, J. An introduction to Plato's Republic. Oxford: Oxford University Press, 1981.

BOBONICH, C. Plato's Utopia Recast: His Later Ethics and Politics. Cambridge: Cambridge University Press, 2002.

DELCOMINET'TE, S. Facultés et parties de l'âme chez Platon. Plato, v. 8, 2008.

FERBER, R. Platos Idee des Guten. 2. ed. Sankt Augustin: Academia Verlag, 1989.

KRÄMER, H. Epekeina tes ousias, Zu Platon, Politeia 509b. Archiv für Geschichte der Philosophie, v. 51, p. 1-30, 1969.

LAFRANCE, Y. La théorie platonicienne de la dóxa. Paris; Montréal: Belles Lettres; Bellarmin, 1981.

LORENZ, H. Desire and Reason in Plato's Republic. Oxford Studies in Ancient Philosophy, v. 27, p. 83-116, 2004.

MARQUES, M. P. Entre aparecer e ser: sobre República V. In: MARTINHO, M. (Org.). I Simpósio de Estudos Clássicos da USP. São Paulo: Humanitas, 2006a. v. 1, p. 247-270.

MARQUES, M. P. Platão, pensador da diferença: Uma leitura do Sofista. Belo Horizonte: Editora da UFMG, 2006b.

MARQUES, M. P. Aparecer e imagem no livro VI da República. In: PERINE, M. (Org.). Estudos Platônicos: Sobre o ser e o aparecer, o belo e o bem. São Paulo: Loyola, 2009. p. 137-166.

MARQUES, M. P. Aparaître et contrariété dans le livre IV de la République. In: BRANCACCI, A.; EL MURR, D.; TAORMINA, D. (Org.). AGLALA: Autour de Platon: Mélanges offerts à Monique Dixsaut. Paris: Vrin, 2010a. p. 319-333.

MARQUES, M. P. Paradoxo e natureza no livro V da República. Kriterion, UFMG, v. 51, p. 429-440, 2010b.

MARQUES, M. P. Contra a teoria de dois mundos na filosofia de Platão (República V 476e-478e)". In: CONTE, J.; BAUSCHWITZ, O. (Org.). O que é metafísica? Natal: UFRN, 2011. p. 245-260. 
NAGY, G. Comparative Studies in Greek and Indic Meter. Cambridge: Harvard University Press, 1974.

NARTORP, P. Platos Ideenlehre: eine Eiführung in den Idealismus. Hamburg: Felix Meiner, 1994.

SANTAS, G. The form of the good in Plato's Republic. In: ANTON, J. P.; PREUSS, A. (Org.). Essays in ancient Greek philosophy. Albany: State University of New York Press, 1983. v.1, p. 232-263.

SHIELDS, C. Unified Agency and Akrasia in Plato's Republic. In BOBONICH, C.; DESTRÉE, P. (Org.). Akrasia in Greek Philosophy. Leiden: Brill, 2007.p. 61-86.

SLINGS, S. R. Platonis Rempublicam. Oxford: Oxford University Press, 2003.

WIELAND, W. Platon und die Formen des Wissens. Berlin: Vanderhoeck \& Ruprecht, 1982.

WHITE, N. P. Plato on Knowledge and reality. Indianapolis: Hackett, 1976. 
